\title{
SABERES ANCESTRAIS: TESSITURAS E ESTAMPAS POÉTICAS NO TEAR DA VIDA
}

\section{CONOCIMIENTOS ANCESTRALES: TEJIDOS Y ESTAMPADOS POÉTICOS EN EL TELAR DE LA VIDA}

\section{ANCESTRAL KNOWLEDGE: POETIC AND PRINTS ON LOOM OF LIFE}

\author{
Denilson Lima Santos ${ }^{1}$ \\ Universidade da Integração Internacional da Lusofonia Afro-Brasileira \\ denilsonlimas@gmail.com
}

\begin{abstract}
Resumo:
Por meio da discursividade ancestral como operador teórico, esse ensaio foi construído para refletir os caminhos poéticos prenhes de conhecimentos. A meta aqui é apresentar a escrita literária de autoras e autores negras e negros como possibilidade de recriar, nas tramas e tessituras das palavras, a grafia da vida. Utilizamos construtos teóricos que possibilitaram observar a literatura, pelo viés da estética das tradições de matriz africana, como aquela que reorganiza a ancestralidade e os modos de vida inscritos no texto. Por fim, percebemos que é impossível pensar a discursividade ancestral sem observar os aspectos filosóficos da dinâmica civilizatória dos povos afrodescendentes na construção da estética literária.
\end{abstract}

Palavras-chave: Discursividade Ancestral, Poética, Dinâmica Civilizatória, Literatura, Saberes.

\section{Resumen:}

A través del discurso ancestral como operador teórico, este ensayo se construyó para reflejar los caminos poéticos preñados de los conocimientos. El objetivo aquí es presentar la escritura literaria de autores y autores negros y negros como una posibilidad para recrear, en las tramas y tejidos de las palabras, la ortografía de la vida. Utilizamos constructos teóricos que permitieron observar la literatura, a través de los rasgos estéticos de las tradiciones africanas, como la que reorganiza la ancestralidad y las formas de vida inscritas en el texto. Finalmente, nos damos cuenta de que es imposible pensar en el discurso ancestral sin observar los aspectos filosóficos de la dinámica civilizadora de los afrodescendientes en la construcción de la estética literaria.

Palabras clave: Discurso ancestral, Poética, Dinámica civilizadora, Literatura, Conocimiento.

\begin{abstract}
Through ancestral discourse as a theoretical operator, this essay was built to reflect the poetic paths pregnant with knowledge. The objective is to present the literary writing of black and black authors and authors as a possibility to recreate, in the words, the writing of

${ }^{1}$ Nesse momento, realiza pós-doutoramento no Programa de Pós-Graduação em Difusão do Conhecimento (DMMDC - UFBA). É Coordenador do Grupo de Estudos, Pesquisa e Extensão em Cultura Intelectual e Linguagens (GEPECIL). Além disso, é Bolsista Produtividade, CNPq, Processo: 306596/2020-2.
\end{abstract}


life. We used theoretical constructs that made it possible to observe literature, through the aesthetic of African traditions, such as that which reorganizes ancestry and the ways of life inscribed in the text. Finally, we realize that it is impossible to think about ancestral discourse without observing the philosophical aspects of the civilizing dynamics of people of African descent in the construction of the aesthetics literary.

Keywords: Ancestral discourse, Poetics, Civilizing dynamics, Literature, Knowledge.

Recibido: 07 de abril de 2021

Aceptado: 07 de junio de 2021

\section{Início de conversa}

Há algum tempo, temos discutido a escrita da ancestralidade na literatura afro-latinoamericana, ou seja, como os saberes ancestrais são ressignificados na estética literária (Santos, Notas 115, Yoruba 15, Intelectualidade 765). Seguimos na perspectiva da ancestralidade e, como sempre, temos afirmado que essa é uma categoria teórica, para pensar as dimensões humanas. Nesse ensaio, delimitaremos nossas discussões a partir de um recorte que leve em conta as reflexões epistemológicas, dialogando com as múltiplas linguagens em que a Ancestralidade seja o "signo que perpassa as manifestações culturais dos negros no Brasil, esparramando sua 'dinâmica para qualquer grupo racial que queira assumir a identidade de africano" (Oliveira, A ancestralidade 23). Em outras palavras, os saberes ancestrais é o fio que tece as experiências do cotidiano e, por isso, a literatura é um instrumento que contribui para dar ao tecido da vida as estampas e as cores que ornamentam a estética ocidental com os desenhos das tradições de matriz africana.

Por esse caminho, a ancestralidade também é vista pela ótica do território usado, para lembrar o geógrafo Milton Santos (Território e Sociedade 2001, Território ensaios 2007), a saber, a ancestralidade é o território onde se encontram corpos e corpus (Cit. em Martins 27). Pessoas que, sequestradas de suas terras, aportaram aqui após uma longa travessia transatlântica e trouxeram impressos no corpo os conhecimentos ancestrais. Para além disso, os saberes africanos nas Américas, compreendidos como espaço de ancestralidade, isto é, "uma geografia de relevos, onde tudo que se evidencia é menos evidência que mistério. O mistério é a estampa impressa no tecido da existência" (Oliveira, Filosofia 247), se constituiu em conjuntos de corpora que foram transmitidos por meio da oralidade, gestualidade e modos de ser e fazer na comunidade. 
Aqui tomamos o conceito de Ancestralidade como uma imensa colcha que é entremeada pelas experiências, cosmovisões e corpos que atravessam territórios e oceanos para ressiginificar a dinâmica civilizatória nessas terras. Para melhor entender, chamamos de discursividade ancestral a escrita, a leitura e a reinvenção das culturas africanas e diaspóricas por meio das múltiplas linguagens como instrumentos de demonstração das heranças estéticas herdadas das tradições de matriz africana. A partir disso, pensaremos quatro dimensões para compreender o processo da discursividade ancestral: a primeira será a dimensão da própria ancestralidade, como aspecto civilizatório. A segunda se refere à da política. A terceira, corresponde à extensão dos saberes, ou seja, outras epistemes reconstruídas para além do Atlântico e a quarta será a influência estética na poética literária.

As dimensões propostas acima nos ajudam a compreender a ideia discursiva que analisamos, neste momento. No entanto, lembramos que faremos a análise das obras contidas nesse ensaio sob a perspectiva de que o conhecimento ancestral também é complementaridade, isto é, altruísmo, pois a ancestralidade é uma categoria de relação "no que vale o princípio de coletividade, pois não há ancestralidade sem alteridade" (Oliveira, Filosofia 257). Por isso, se faz relevante analisar as produções literárias de autoras e autores que fazem emergir em seus textos os saberes revisitados da ancestralidade. Aqui apresentamos poemas de Solano Trindade (1908-1974), Conceição Evaristo (1946- ), Gwellwaar Adún (1968 -) e Lívia Natália (1979-).

Dentro dessa ideia de conjunto de indivíduos que compartilham saberes e fazeres os quais se reatualizam como princípio contínuo das vivências, pensamos a escrita da ancestralidade como processo discursivo contínuo e de caráter político, libertador e de autonomia dos sujeitos. Em outras palavras, a discursividade ancestral é uma ação de recriação, tal qual já postulou Paulo Freire que só “existe saber na invenção, na reinvenção, na busca inquieta, impaciente, permanente, que os homens fazem no mundo, com o mundo e com os outros (58). Nessa linha de pensamento, a ancestralidade também se inscreve, para além dos corpos, na grafia dos sujeitos e na estética produzida por eles.

$\mathrm{Na}$ esteira da escrita e da reescrita de saberes ancestrais, a linguagem se transforma em duas possibilidades: a primeira é a invasão de outras epistemologias e a segunda é ação dialógica entre os sujeitos, nesse caso autores e leitores. Em outras palavras, os saberes ancestrais são tecidos a partir de um processo ético e empático. 
Eu devo entrar em empatia com esse outro indivíduo, ver axiologicamente o mundo de dentro dele tal qual ele o vê, colocar-me no lugar dele e, depois de ter retornado ao meu lugar, completar o horizonte dele com o excedente de visão que desse meu lugar se descortina fora dele, convertê-lo, criar para ele um ambiente concludente a partir desse excedente da minha visão, do meu conhecimento, da minha vontade e do meu sentimento (Bakhtin 23).

Esse caráter do excedente de visão, apontado por Bakhtin, contribui com a ideia de discursividade ancestral como a relação entre as pessoas, ou seja, a interação pela coletividade. Essa relação é mediada pela força vital: o Axé. Há, dessa forma, na experiência do cotidiano, no modo de vida da comunidade, a comunhão do conhecimento. Ao seguir essa trilha, percebemos que a discurividade ancestral se constrói pela "energia-palavra” (Oliveira, Filosofia 47), ou seja, o axé desenhado pelas palavras com profundidade semântica para que o sujeito possa entender o mundo e se entender por meio da criação estética. Tudo isso é possibilidade dinamizadora do mistério engendrado pela função exusíaca da linguagem. Pois no contexto social de racismo e apagamento da cultura negra, por exemplo, se faz necessário pensar que

se o branco constitui uma privação do pensar negro, efetivada através das várias formas de censura, até que se tornasse autocensura, aquele mesmo pensar passou a se desvencilhar das amarras e das ataduras, ao fazer uso da função exusíaca da linguagem, libertando-se através do monólogo autoreflexivo e do diálogo polarizado com o outro" (Cuti 25).

Podemos dizer que há uma estética exusíaca da linguagem na relação da criação estética e a sua recepção. Concordamos com Cuti quando ele postula o conceito de função exusíaca da linguagem, a saber,

Exu, orixá que abre os caminhos, que está além do bem e do mal, instaura a polaridade para operar a síntese. Energia pessoal do dinamismo. Ao funcionar de forma desestabilizadora, dinamizadora das contradições e libertadora, a linguagem estará realizando a sua função exusíaca (25).

Em suma, a discursividade ancestral é desestabilizadora, dinamizadora das contradições e libertadora porque se posiciona em confronto com a estética hegemônica. Torna-se assim, a linguagem, o corpo e o saber elementos que reinscrevem as culturas diaspóricas em epistemes moventes. E ao mesmo tempo permite uma visão crítica da língua(gem), pois essa "tem cor e é uma possibilidade de luta e resistência ao projeto de 
racialização do pensamento moderno, que não só cria opressão, mas cria a língua como seu processo gerador primordial" (NASCIMENTO, 2019, p.23).

Outro tanto podemos dizer sobre a relação, aqui tecida, entre a discursividade ancestral e a poética. Para isso, por mais que a tradição ocidental tenha seu legado no pensamento estético de Aristóteles, que não será nosso foco fazer essa discussão clássica nesse momento, trazemos o recorte de poética como inscritura, que significa a "instância da expressão cultural cujo entendimento se encaminha para o de uma relação simultânea entre diferenciados códigos e linguagens artísticas" (Queiroz, As inscrituras 13). Ressaltamos que a poeticidade de escritoras e escritores, que mais à frente apresentaremos, dialoga com as tessituras do conhecimento ancestral que emergem das relações sociais e textuais entre os sujeitos poéticos (aqui entendido como autor e sujeito lírico ou personagem) e os receptores, nesse caso, os leitores. Sob a perspectiva de variedades de códigos e de linguagens, caminhamos na trilha dos saberes construídos na Diáspora africana.

Diante do exposto, veremos como a discursividade ancestral das tradições de matriz africana se ressignifica na escrita de autoras e de autores afrodescendentes. No entanto, essa categoria não se aplica só a eles. Sabemos que saberes ancestrais são construídos em comunidades indígenas, quilombolas e de imigrações de várias partes. O que queremos ressaltar é a ancestralidade como categoria analítica e relacional de contínua construção de saberes e coletividades a partir das africanidades.

\section{Aprendo a ler para ensinar meus camaradas}

Se há uma coisa que podemos perceber na história do povo negro no Brasil, especificamente o Movimento Negro Brasileiro é que ele é educador, com já assinalou Nilma Lino Gomes (Cit. em, O movimento educador 13). Nesse sentido, a construção de saberes do povo negro é a proposta de "práticas decoloniais latino-americanas" (Gomes, O movimento negro e a Intelectualidade 224) e visibilizadoras de outras epistemologias. Tais reflexões serão necessárias para pensarmos a poética como processo pedagógico e contra-hegemônico.

Dito isto, desde as linhas escritas pela estética romântica de Maria Firmina dos Reis (1822-1917), passando por Carolina Maria de Jesus (1914-1977) e desaguando em tantas outras e outros, percebemos que há um fio condutor em suas escritas, a saber, a criação 
estética de quem está à margem. De quem não goza dos privilégios de estar no cânone literário, mas domina a discurso literário.

Não obstante, o pensamento de escritoras negras no Brasil, tal qual Lélia Gonzalez (1935-1994), fundamenta a visão da educação e dos saberes transplantados para estes trópicos que insistem em negar a contribuição africana à cultura nacional. Aqui, na Améfrica Ladina (Gonzalez 69), se estabelece a recriação dos saberes afrocentrados, isto é, uma amefricanidade. Como exemplo disso, Lélia Gonzalez cita a Jamaica, com a predominância dos povos Akan; no Brasil os povos iorubas, bantus e ewe-fon. Do mesmo modo, amefricanidade é a proposta de pensar os construtos epistemológicos "de nossos antepassados no continente em que vivemos, inspirados em modelos africanos" (Gonzalez 77). Assim, podemos perceber o entremear da ancestralidade na construção de saberes civilizatórios no eixo sul. A instauração do suleamento por meio da discursividade ancestral.

Diante do legado e das discussões sobre esse território ser espaço de amefricanidades, podemos entender a relação do conceito de inscritura traçado por Amarino Queiroz:

A ideia de inscritura de que nos estamos valendo aponta para uma categoria artística cuja representação é movente, fluida, aberta, inclusiva, manifestada pelo empenho de interação entre o oral e o escrito, mas assimilando e absorvendo elementos outros como o musical, o cênico e o pictográfico. Calcada nessa dinâmica de apropriação, desapropriação e reapropriação constantes, sua base expressiva é a performatividade (114).

A partir da inscritura como processo de interação entre o oral e o escrito, pensamos a poética como expressão do saber-estético. Nesse sentido a palavra como potência movente se torna a práxis coletiva, pois,

se dizer a palavra verdadeira, que é trabalho, que é práxis, é transformar o mundo, dizer a palavra não é privilégio de alguns homens, mas direito de todos os homens. Precisamente por isso, ninguém pode dizer a palavra verdadeira sozinho, ou dizê-la para os outros, num ato de prescrição, com o qual rouba a palavra aos demais. (Freire 78)

Desse modo, a discursividade ancestral cumpre o papel de energia-palavra, "palavra verdadeira" no espaço da coletividade. Como já sabemos: "Ninguém educa ninguém, ninguém educa a si mesmo, os homens se educam entre si, mediatizados pelo mundo" (Freire 
68). É na interação comunitária que os conhecimentos ancestrais se constroem e reconstroem. É bom lembrar que o saber e o tempo para as sociedades africanas não são estáticos, mas dinâmicos. "Para o africano tempo é dinâmico e o homem não é prisioneiro de um mecânico remoto cíclico, podendo lutar sempre pelo desenvolvimento de sua energia vital" (Oliveira, Filosofia 51). Como exemplo disso, Eduardo Oliveira nos apresenta um poema Songai:

Não é da minha boca.

É da boca de A, que o deu a B, que o deu a $C$, que o deu a $\mathrm{D}$, que o deu a $\mathrm{E}$, que deu a F, que o deu a mim. Que esteja melhor na minha boca do que na dos Ancestrais (51).

O saber é transmitido, mas não é cristalizado. Aquele que transmite, o faz em um dado tempo e aquele que aprende tem seu tempo e, assim, transforma o que aprende em outras maneiras de dizer e outros modos de saber. O que é passado de A à F e depois a "mim" é palavra (conhecimento ancestral) direito de todos. É dinâmica porque se transforma e é transformada por aquele que aprende. Ele pode refazer o conhecimento herdado da coletividade. Daí, percebemos que a sabedoria ancestral se instaura na poética e na performatividade do oral e do escrito como modo de vida em comunhão do sujeito consigo, com o outro e com o mundo.

\section{Saber, sabor e poeticidade ancestral}

Saber, palavra de origem latina sapere o mesmo que ter sabor, se transmutou para o sentido daquele que conhece sobre o mundo, sobre as coisas. Aqui, nos referimos ao saber como um aspecto civilizatório dos princípios negro-africanos. Em linhas gerais pensamos que

São aspectos civilizatórios característicos da cultura negra, re-construída no contexto brasileiro, preservando, entretanto, sua matriz africana. Pensamos aqui na perspectiva de herança, considerando a produção dessa cultura na história do povo negro, pois não existe identidade inata. A identidade de um povo também é uma indústria da história. Como a cultura negra é marcada pela reversibilidade, afugentamos de nós o conceito linear de história. É exatamente por operar restituições simbólicas tradicionais em 
contextos históricos contemporâneos que a cultura negra exerceu seu poder de sedução sobre a sociedade brasileira, re-introduzindo elementos culturais africanos no intricado cadinho da identidade brasileira (Oliveira, Cosmovisão 85).

Mais que poética, pensamos a poeticidade como território simbólico-cultural.

Pensar a cultura negra é pensar a reterritorialização dos negros no Brasil. O território afro-Brasileiro não é espaço físico africano, mas a forma como os negros brasileiros singularizaram o território nacional. O espaço físico reterritorializado é um espaço simbólico-cultural. Esse território, singularizado pela cultura negra, por seu real vivido, por sua filosofia imanente, por sua dinâmica civilizatória, marcou definitivamente a formação social brasileira. Foram os aspectos civilizatórios africanos que, reinterpretados no Brasil, desenhanaram o projeto ético-político dos afrobrasileiros (Oliveira, Cosmovisão 85).

Assim, o que chamamos aqui de território simbólico-cultural, pode ser observado na poética de Solano Trindade (1908-1974):

$$
\begin{aligned}
& \text { Xangô } \\
& \text { "Mariô ê } \\
& \text { Mariô á } \\
& \text { Iemanjê } \\
& \text { Iemanjá" }
\end{aligned}
$$

Até a lua cantava,

E dançava,

Este canto nagô,

O mar suspirava,

O mar soluçava,

Era água africana,

Na praia do Pina,

No xangô da baiana

(126).

Sim, queremos abordar a escrita da ancestralidade, a partir dos elementos da religiosidade de matriz africana, ou melhor, das tradições religiosas de matriz africana reelaboradas em uma poética que verbaliza o oral e o escrito como performatividade verbal. No poema de Trindade, percebemos os aspectos civilizatórios africanos entrelaçados com 
outros espaços simbólicos. Como assevera Eduardo Oliveira, aqui nos interessa os significados e sentidos (Cit. em Filosofia 85) dos saberes religiosos como discursividade. O território simbólico-cultural emerge na poesia de Solano Trindade como diálogo entre o sujeito poético e o público receptor mediado pela recuperação da memória (Cit. em Queiroz, Entre margens 145). Daí, compreende-se o jogo das palavras que dão sentido ao todo do poema acima. As heranças do continente africano, no Brasil, ressurgem na lírica do mano Solano não só pela musicalidade, mas pela riqueza da universalidade: praia do Pina no Recife é o locus simbólico onde as águas se ressignificam a partir da "água africana" e do "xangô da baiana"2.

Como temos exposto, os aspectos civilizatórios afrodescendentes são transmitidos pelas tradições religiosas e reinscritos na poética performativa de Solano Trindade e "escrevividos"3 por Conceição Evaristo:

Do velho ao jovem

Na face do velho as rugas são letras, palavras escritas na carne, abecedário do viver.

$\mathrm{Na}$ face do jovem

o frescor da pele

e o brilho dos olhos são dúvidas.

Nas mãos entrelaçadas

de ambos, o velho tempo funde-se ao novo, e as falas silenciadas explodem.

O que os livros escondem, As palavras ditas libertam.

\footnotetext{
${ }^{2}$ Segundo Nei Lopes (2004) na Enciclopédia brasileira da Diáspora africana, Xangô, além de ser uma deidade iorubana relacionado ao trovão e ao fogo, é uma "denominação genérica dos cultos africanos de origem sudanesa em Pernambuco" (p.687).

3 Aqui fazemos o jogo de sentidos e significados do conceito escrevivência de Conceição Evaristo. Escrevivência é pensar como a vida pode ser escrita nos sujeitos e como estes podem escrever sobre tudo que vive no mundo. Recomendamos a entrevista a autora disponível em:https:/www.bn.gov.br/acontece/noticias/2015/11/entrevista-com-conceicao-evaristo
} 
E não há quem ponha

Um ponto final na história

Infinitas são as personagens...

Vovó Kalinda, Tia Mambene,

Primo Sendó, Ya Tapuli, Menina Meká, menino Kambi, Neide do Brás, Cíntia da Lapa,

Piter do Estácio, Cris de Acari, Mabel do Pelô, Sil de Manaíra,

E também de Santana e de Belô

e mais e mais, outras e outros...

Nos olhos do jovem

também o brilho de muitas histórias.

E não há quem ponha

um ponto final no rap

É preciso eternizar as palavras

da liberdade ainda e agora...

(51).

Algo que gostaríamos de chamar a atenção é a questão dos significados e dos sentidos das tradições africanas que emergem no texto literário. Já apontamos o processo de inscritura do verbo, conceito abordado por Amarino Queiroz (As inscrituras 114). Esse mesmo autor, no texto citado anteriormente, "Entre margens e centros: a poesia urbana de Mano Solano e outros manos" recupera a relação entre Solano Trindade e o Hip Hop. Historicamente, aqui no Brasil, esse movimento ganha força em São Paulo, lugar onde a migração nordestina "ditaria um comportamento assemelhado [a condição de migrantes dos "manos" do Hip Hop], não apenas do ponto de vista da resistência cultural, mas também no que concerne às condições de sobrevivência e inserção social" (Queiroz, Entre margens 148). É possível, dessa maneira, entendermos que "as palavras ditas libertam”, pois essas se apresentam no Rap, como heranças de outras histórias mencionadas no poema de Conceição Evaristo.

Se Solano Trindade é o "avô dos rappers", como assinala Amarino Queiroz, podemos dizer que Conceição Evaristo é a tia querida contadora das histórias que não nos deixam esquecer nossas origens. Talvez, possamos dizer que tanto Trindade como Evaristo prenunciam o que Ana Lúcia Silva Souza chamará de letramentos de reexistência, ou seja, “a reinvenção de práticas que os ativistas realizam, reportando-se às matrizes e aos rastros de uma história ainda pouco contada, nos quais os usos da linguagem comportam uma história 
de disputa pela educação escolarizada ou não" (37). De fato, as "incrituras do verbo" e os "letramentos de reexistência" são categorias que apontam para os saberes ancestrais como discursividade operadora dos aspectos históricos, políticos e estéticos no marco civilizatório das tradições africanas nesses trópicos.

Outra possibilidade de leitura do saber ancestral aparece na escrita literária de Gwellwaar Adún. No poema "Cidadão dendê II":

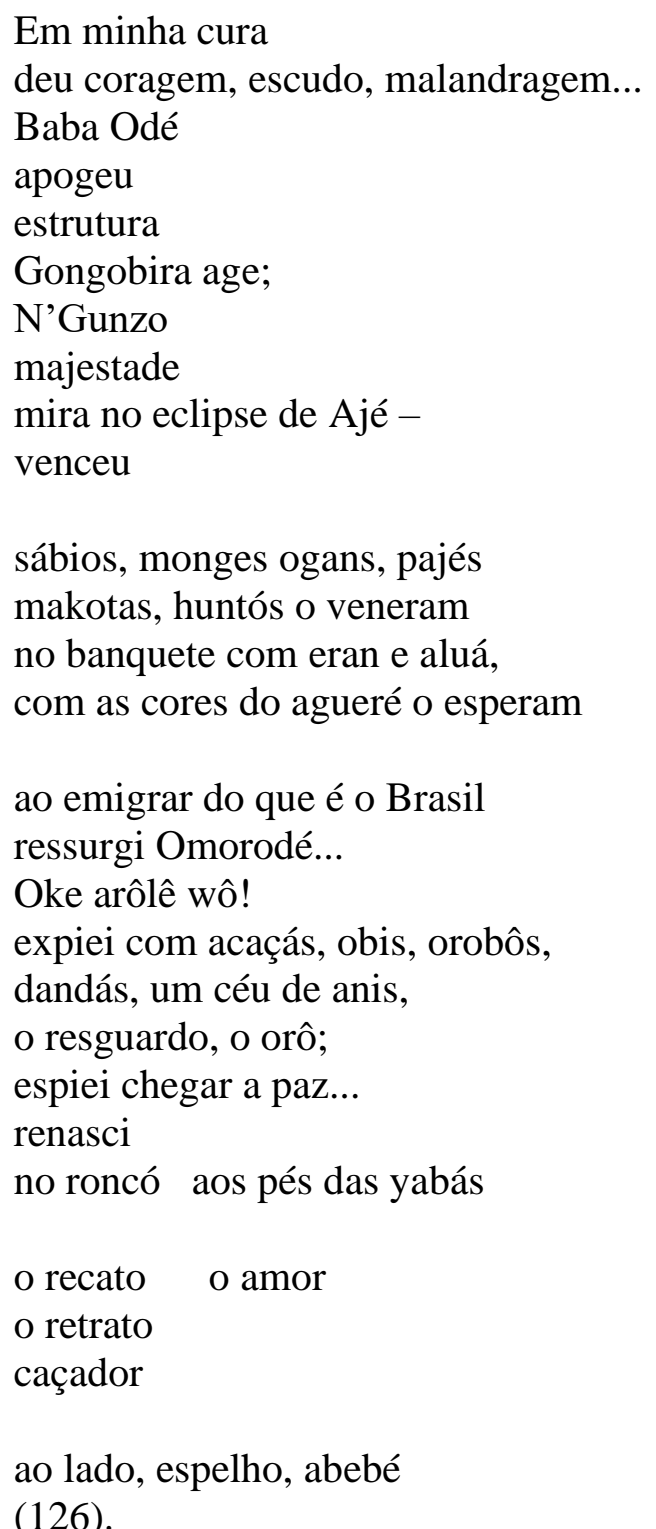

No percurso lírico, o poeta ressignifica os saberes ancestrais no contexto pedagógico. O eu-lírico, enuncia sua trajetória no culto de candomblé: "Em minha cura". A ritualística da 
iniciação requer imprimir no corpo do noviço os sinais da nova vida, isto é, uma nova caminhada para e com o Orixá, no caso do poema, Oxossi, o mesmo que Odé, o caçador. Daí, em uma postura metalinguística em que a palavra é mote para significado da própria palavra, percebemos o uso do léxico das línguas africanas, especificamente as do tronco banto e ioruba, como processo que reescreve a ancestralidade em um rito iniciático das palavras.

Aquele que imerge nos conhecimentos propiciados pela ancestralidade africana, renasce no Brasil, no caso do eu-lírico, “Omorodé”, isto é, filho de Odé, filho do caçador. Esse título é uma das derivações de um outro: Omó Orixá, ou seja, filho do Orixá, na "tradição religiosa iorubana, denominação genérica que se dá ao iniciado, ao filho-de-santo, seja ele iaô [noviço] ou não" (Lopes 497). Esse jogo de palavras no poema reitera a potência da energia-palavra que performatiza outros saberes por meio da poética.

Diante disso, percebemos que os saberes ancestrais se reorganizam sob a confluência da discursividade. É visível que o modo de ser e de dizer são possibilidades de aprender com o marco civilizatório africano. Assim, podemos destacar na poética ancestral, apresentada nos textos literários acima, dois aspectos: o primeiro aquele que é político e organiza a dimensão histórico-social dos povos africanos na Diáspora, ou seja, esses povos têm uma história em comum: a escravidão. O segundo é a reescrita dos saberes por meio da discursividade ancestral, pois nesta resguarda a estética, significados e sentidos das epistemes africanas.

De igual modo, as águas, mote e tema na obra de Lívia Natália, nos fazem pensar nas incursões da palavra como afluentes da discursividade ancestral na obra dessa poeta. Especialmente no poema "Asé” encontramos o espaço simbólico da palavra-energia:

Asé

Sou uma árvore de tronco grosso.

Minha raiz é forte, nodosa, originária, betumosa como a noite.

O sangue, ejé que corre caudaloso, lava o mundo e alimenta o ventre poderoso de meus Orixás. A cada um deles dou de comer 
um grânulo vivo que sou

com uma fé escura.

(Borrão na escrita do deus de olhos docemente azuis).

Minha fé é negra,

e minha alma enegrece a terra

no ilá

que de minha boca escapa.

Sou uma árvore negra de raiz nodosa.

Sou um rio de profundidade limosa e calma.

Sou a seta e seu alcance antes do grito.

E mais o fogo, o sal das águas, a tempestade

e o ferro das armas.

E ainda luto em horas de sol obtuso

nas encruzilhadas.

(35).

A metáfora da árvore nos é apropriada pois Amarino Queiroz já nos chamou a atenção sobre a árvore baobá (conhecida também por: adansonia, baobab, bondo, embondeiro, imbondeiro, micondó, mulambe e monkey-brad-tree). O Baobá

caracterizava-se assim um espaço real e simbólico para a tomada de decisões coletivas e para a transmissão do saber e do conhecimento, fazendo com que a expressão do verbo, ao mesmo tempo lúdica e sagrada, se produzisse como um prolongamento da fala na corporeidade do gesto, elemento fundamental para a perpetuação da memória e para a manutenção das identidades culturais (As inscrituras 120).

E nesse mesmo sentido de recuperar a corporeidade da memória é que o eu-lírico do poema acima, “Asé”, se projeta na escrevivência do sangue como texto, isto é, tal qual a seiva arbórea que vivifica o baobá, a experiência ancestral nas vozes do poema é uma maneira de compreender o lugar no mundo daquele sujeito que participa das tradições de matriz africana. Ao mesmo tempo há uma reescrita da experiência ancestral como reapropriação epistemológica. $\mathrm{O}$ eu-lírico apreende o mundo a partir da conexão com a natureza em sua totalidade.

Nesse caminho elegíaco, a figura feminina constrói as relações simbólicas entre o sagrado e sua compreensão de mundo (natureza e os outros sujeitos). Desde a ideia de ser "um rio de profundidade limosa e calma", referência ao orixá Oxum, até a expressão: "Sou 
a seta e seu alcance antes do grito", em alusão ao orixá Oxossi, percebemos que há um cosmocanto ancestral que se aprende no cotidiano da religiosidade da tradição de matriz africana. No jogo poético há algo que dialoga com o rito ancestral. A palavra-energia é reelaborada no tecer lírico de Lívia Natália como instrumento de ser e entender-se como axé. É a dinâmica do saber sendo reelaborado.

Não há dúvida de que há no poema citado anteriormente, a recuperação do conhecimento que veio da África e se reinventa no papel da mulher na comunidade. O sagrado se revela na palavra. Essa mulher que se ampara na fé para enegrecer a terra produz a potência feminina da vida pela energia-palavra. E por essa via a discursividade ancestral contribui para outorgar aos leitores a palavra que pode ser reelaborada, isto é, dita de outra maneira quando esses as leem, as pronunciam o as reescrevem.

\section{Considerações finais}

É impossível pensar a discursividade ancestral sem observar, ou melhor, sem levar em conta a dialética social e a estrutura dos aspectos filosóficos da dinâmica civilizatória dos povos afrodescententes.

Não queremos reduzir os saberes das tradições de matriz africana a um aspecto ou a uma possibilidade de reinterpretação da ancestralidade dos povos de África nessas terras. Pelo contrário, voltar o olhar para as epistemes desses povos que construíram valores e conhecimentos aqui é estar atento à pluralidade que a cosmovisão africana imprime em nossa cultura.

Mergulhar nas águas ancestrais é se permitir aprender sobre outros modos de ver o mundo. É dialogar com outridades, com a coletividade. Os aspectos das tradições africanas que foram e são reescritas por mulheres e homens são, na verdade, a reconstrução dos conhecimentos por meio da palavra e do diálogo que possibilitam aos sujeitos reconstruir a escrevivência de suas realidades. Esse processo emerge na estética literária como projeto de "eternizar as palavras da liberdade ainda e agora", como já sinalizou Conceição Evaristo.

\section{REFERÊNCIAS}

Adún, Gwellwaar. Desinteiro. Ogum’s Toques Negros, 2016. 
Bakhtin, Mikhail. Estética da criação verbal. Martins Fontes, 1994.

Cuti, Luiz Silva. “O texto e o leitor afro-brasileiro". Poéticas afro-brasileiras, edição de Maria Nazareth Soares Fonseca et al. Mazza/PUC Minas, 2002, pp 19-36.

Freire, Paulo. Pedagogia do oprimido. Paz e Terra, 1987.

Gomes, Nilma Lino. “O movimento Negro e a intelectualidade negra descolonizando os currículos". Decolonialidade e pensamento afrodiaspórico, edição de Joaze Bernadino-Costa, Nelson Maldonado-Torres y Ramón Grosfoguel. Autêntica Editora, 2019, pp.223-246.

Gomes, Nilma Lino. O movimento Negro educador. Vozes, 2017.

Gonzalez, Lélia. “A categoria político-cultural de amefricanidade”. Tempo Brasileiro, núm. 92/93, 1988, pp. 69-82.

Ipeafro. Acervo, https://ipeafro.org.br/. Consultado em 20 de junho de 2019.

Lopes, Nei. Enciclopédia brasileira da Diáspora africana. Selo Negro, 2004.

Martins, Leda. Afrografias da memória: O reinado do Rosário no Jatobá. Mazza, 1997.

Nascimento, Gabriel. Racismo Linguístico: os subterrâneos da linguagem e do racismo. Letramento, 2019.

Natália, Lívia. Água Negra e Outras Águas. EPP, 2016.

Oliveira, Eduardo. Cosmovisão Africana no Brasil: elementos para uma filosofia afrodescendente. Popular, 2006.

---. A ancestralidade na encruzilhada. Curitiba, Popular, 2007.

---. Filosofia da ancestralidade: corpo de mito na filosofia da educação brasileira. Popular, 2007.

Queiroz, Amarino Oliveira de. As inscrituras do verbo: dizibilidades performáticas da palavra poética africana. Univerdidade Federal de Pernambuco, 2007.

---. "Entre margens e centros: a poesia urbana de mano Solano e outros manos". Revista contexto, núm. 26, 2014, pp. 144-156.

Santos, Denilson Lima. "Notas para Pensar a Intelectualidade dos Autores Afro-Latinos: A Discursividade Iorubá e Banta de Abdias do Nascimento e Manuel Zapata de Olivella”. Meridional Revista Chilena de Estudios Latinoamericanos, núm. 4, 2015. pp. 115-142. 
Artículo. Denilson Lima Santos. "Saberes ancestrais: tesituras e estampas poéticas no tear da vida"

---. Yorubas y bantúes en la discursividad ancestral: estudio comparado de Sortilégio II (1979) de Abdias do Nascimento y de Changó, el gran putas (1983) de Manuel Zapata Olivella. Universidad de Antioquia, 2015.

---. "Intelectualidade e discursividade ancestral de Abdias do Nascimento e Manuel Zapata Olivella”. Revista ABPN, núm. 10, 2018, pp. 765-793.

Santos, Milton. "O dinheiro e o território". Território, territórios ensaios sobre o ordenamento territorial, edição de Milton Santos et al. Lamparina, 2007.

---. Território e sociedade — Entrevista com Milton Santos. Perseu Abramo, 2001.

Souza, Ana Lúcia Silva. Letramentos de reexistência: poesia, grafite, música, dança: HipHOP. Parábola, 2011. 